\title{
Auditory Brainstem Response Latencies of Infants and Maternal Exposure to Environmental Toxic Products
}

\author{
Charlotte M. Chiong, ${ }^{1,2}$ Enrique M. Ostrea, Jr., ${ }^{3,4}$ Erasmo Gonzalo DV. Llanes, ${ }^{1,2}$ Esterlita T. Villanueva-Uy,, ${ }^{4,5}$ \\ Alexis L. Reyes, ${ }^{4,5}$ Teresa Luisa I. Gloria-Cruz ${ }^{1,2}$ and Maria Rina T. Reyes-Quintos ${ }^{1,2}$ \\ ${ }^{1}$ Department of Otorhinolaryngology, College of Medicine and Philippine General Hospital, University of the Philippines Manila \\ ${ }^{2}$ Philippine National Ear Institute, National Institutes of Health, University of the Philippines Manila \\ ${ }^{3}$ Department of Pediatrics (Neonatal Medicine), School of Medicine, Wayne State University, Detroit, Michigan, USA \\ ${ }^{4}$ Institute of Child Health and Development, National Institutes of Health, University of the Philippines Manila \\ ${ }^{5}$ Department of Pediatrics (Developmental Pediatrics), College of Medicine and Philippine General Hospital, University of the Philippines Manila
}

\begin{abstract}
Objective. To explore the effects of pesticide exposure on the auditory system, specifically on hearing status based on auditory brainstem responses.

Methods. A cohort of pregnant women was identified in several communities in a rural area from April 2002 to February 2003 and followed up until delivery. Mother-infant dyads were assessed for exposure to pesticides. Maternal and fetal exposures to environmental toxic products were determined by measuring levels in maternal hair and blood, and infant cord blood, hair, and meconium, respectively. Hearing status was measured using otoacoustic emissions (OAE) and confirmed by diagnostic auditory brainstem responses (ABR) measured at 80 , 60 , and 40 decibels. Waves I, III, $V$ were identified and absolute latencies measured, including inter-peak latencies from waves IIII, I-V, and III-V. Pesticide exposure was then correlated with latencies of Waves I, III, V, and interpeak latencies of waves I-III, I$\mathrm{V}$, and III-V. Hearing loss and pesticide exposures were correlated with Griffiths Mental Development Scores (GMDS).
\end{abstract}

Results. Significant delays in the ABR wave latencies were noted in the group with exposure to pesticides. Propoxur was the most common toxic product detected in infants and meconium the best substrate for its detection. There was a $1.4 \%$ risk of hearing loss with exposure to propoxur $(R R=0.52(0.12-2.30), p=$ $0.06)$, a $6.25 \%$ risk with cypermethrin exposure $(R R=4.53(0.61$ $33.64), p=0.10)$ and $6.25 \%$ risk with pretilachlor exposure (3.13 (0.44-22.30), $p=0.07)$. Griffith's Mental Developmental Scale scores (GMDS- hearing and speech subscale and general quotient scores) were not significantly different between exposed and unexposed groups. However, three infants with positive exposures and hearing loss had below average, or low to average scores using this scale.

Conclusion. Maternal exposure to environmental toxic products may affect the auditory pathway in infants at birth. Pregnant

\footnotetext{
Corresponding author: Charlotte M. Chiong, MD

Philippine National Ear Institute

National Institutes of Health

University of the Philippines Manila

623 Pedro Gil Street, Ermita, Manila 1000 Philippines

Telephone: +632 5548400 loc. 2072

Email: charlotte_chiong@yahoo.com
}

women should limit their exposure to such toxic products in order to avoid neurodevelopmental effects particularly on hearing because this is very important in the critical stage of language and speech development.

Key Words: auditory brainstem response, environmental toxic product exposure, pesticides, hearing status, neurotoxicants, propoxur, cyfluthrin, pretilachlor

\section{Introduction}

In a tropical primarily agricultural country like the Philippines, environmental toxic products such as pesticides and insecticides abound in most homes given previous reports of high prevalence of infestations with pests such as flies $(97.7 \%)$, roaches $(89.8 \%)$ and mosquitoes $(97.6 \%) .{ }^{1}$ Use of these products is deemed justified when the significant prevalence of pests and vector-borne diseases is considered, whether in the farm or at home. The acute toxic effects of these products seen in acute poisoning have already been identified, and include effects on the central nervous system manifesting as varied neurological symptoms and behavioral changes. ${ }^{2}$ Profound bilateral sensorineural hearing loss has been associated with peripheral neuropathy in the extremities following acute poisoning from combined mixture of $75 \%$ malathion and $15 \%$ metamidophos. ${ }^{3}$

The auditory pathway has also not been spared from neurotoxin effects of other substances such as lead, $4,5,6$ cocaine, ${ }^{7}$ and methylmercury, ${ }^{8}$ as established with delayed brainstem auditory evoked potentials. Combined exposure to organophosphates and pyrethroid insecticides revealed an associated high frequency hearing loss in $57 \%$ of exposed Brazilian farm workers. ${ }^{9}$ Central auditory dysfunction assessed through pitch pattern sequence and duration pattern sequence showed $56 \%$ of exposed workers with central hearing disorder and a relative risk of 7.58 for the group exposed to insecticides (95\% CI 2.9-19.8) when compared to the non-exposed group. ${ }^{10}$

In the rural areas where numerous chemicals are released in the environment, it would be sensible to assess the possibility that such exposures can also affect the auditory system. Constant use of these products results in 
sub-clinical exposure of humans albeit in much lower concentrations that are not enough to cause acute toxic effects. Chronic sub-clinical effects seem difficult to assess considering the intricate measurement of use and subsequent exposure. Despite this, it is important to determine the presence of such products in a community, demonstrate exposure to such products, and identify possible short- and long-term effects. This would help in regulating and possibly modifying behaviors regarding use of such products especially in pregnant women who may unduly increase the risks to the fetus with their exposure.

Previous studies ${ }^{1,8}$ have shown that appropriate assessment of exposure maybe performed through analysis of various biological matrices, of which maternal hair was found to be the most robust for detecting maternal exposure to pesticides and meconium found to be the most sensitive for establishing exposure in infants. ${ }^{1,8}$ These studies found propoxur to be the most common toxic product found in meconium in about $23.8 \%$.

Correlation of neuro-development determined through GMDS and hearing status by screening with OAE and ABR showed good correlation between the presence of hearing loss and developmental delay. ${ }^{11}$ This study looks at the possible effects of pesticide exposure on the infantile auditory system specifically looking at changes in ABR wave latency measures in those with maternal and infant exposures to environmental toxic products.

\section{Methods}

All pregnant women consulting at the Bulacan Provincial Hospital from April 2002 to February 2003 were identified and recruited to participate in the study. Study participants who did not consent and who failed to submit for follow-up were excluded. The study was approved by the Human Investigation Committees at both Wayne State University and the University of the Philippines Manila. Informed consent was obtained for collection of demographic information, blood and hair samples from the mothers and their infants, meconium samples from newborns, and newborn hearing screening and diagnosis using OAE with ABR testing. Maternal blood and hair samples were collected upon recruitment and delivery, while infant cord blood samples were obtained at birth, infant hair and meconium samples were obtained later in the nursery. To ensure sample adequacy for analysis, collection of samples were pursued in homes of the study participants. Hair was taken from the nape or base of the scalp with the size of a pencil eraser in diameter. Meconium was collected from diapers during the first 2 days of life. Methods of collection and preparation of specimens and measurement of pesticides in various specimens have been extensively described in previous articles related to the study. ${ }^{1,8}$ Pesticides were measured in micrograms/deciliter.
Newborns of identified pregnant mothers underwent OAE (Welch Allyn®Audiopath EOAE Screener 29230) and ABR (Interacoustics EP15) testing and assessment of mental development by developmental pediatricians at 6, 12 and 24 months using the GMDS - locomotor, personal-social, hearing and speech, hand and eye coordination, and performance tests. ${ }^{11}$ The presence of OAEs will show a 'pass' result, and the absence of OAEs will show a 'refer' result, suggesting normal and abnormal cochlear functions, respectively. ABR recorded with standard machine followed American National Standards Institute (ANSI) standards. Determination of the presence of wave $\mathrm{V}$ after introducing clicks sound at different intensities (from 100 decibels $(\mathrm{dB})$ to $30 \mathrm{~dB}$ ) was performed. Evaluation of the ABR tracings to determine presence of waves I, III, V and their inter-peak latencies (I-III, I-V, III-V) in milliseconds were performed. Infants were classified as having normal hearing if wave $\mathrm{V}$ was present at or below $40 \mathrm{~dB}$ suggesting possible normal auditory pathway, and with hearing loss if wave $\mathrm{V}$ was present at greater than $40 \mathrm{~dB}$ suggesting possible abnormal auditory pathway. The latencies of wave I, III, V were determined to determine any delay in the appearance of the response, indicating possible insults in the auditory pathway.

The samples were analyzed for commonly used pesticides: cyfluthrin, propoxur, chlorpyrifos, cypermethrin, pretilachlor, bioallethrin, malathion, diazinon, transfluthrin, lindane and DDT. The pesticides measured included most of the major ingredients of different preparations of insecticides and pesticides. In the Philippines, there are 17 various preparations such as sprays, vaporizer, mats, mosquito coils, moth bag and oil spray. Maternal and infant exposures to several pesticides and metabolites were correlated with auditory brainstem response latencies to determine possible associations.

\section{Results}

There were 686 newborns (365 males (53.2\%) and 321 females $(46.8 \%)$ ) with data on maternal and infant exposure to pesticides and auditory brainstem responses. Mean age of babies on the day of testing is 2 months $( \pm 2.63)$, with $72.7 \%$ tested at 2 months. At 3 months, $78.57 \%$ of all the babies could undergo ABR testing and 100\% were tested by 12 months of age (Table 1). Fifteen infants were noted to have significant hearing loss, with $47 \%$ bilateral and only the right or left ear abnormal in 53\% (Table 2). As shown in Table 3, the subjects had no differences in latency measures between the left and right sides for all the stimulation intensities utilized except for delay in IPL I-III on the left at $80 \mathrm{db}$ stimulation, and wave III and IPL I-III significantly delayed in the left after $40 \mathrm{db}$ stimulation. At $60 \mathrm{db}$, no differences were noted between the right and left ears. It was considered important to look at latency measures separately for the right and left to detect evidence of right and left differences 
and if present report these separately for comparison to those with notable hearing loss. As detailed in Table 4, there were nine pesticides with positive exposures measured in meconium, the best matrix for infant exposure with levels of propoxur, diazinon, malathion, bioallethrin, pretilachlor, DDT, cyfluthrin, cypermethrin, and DDE. The highest frequency of exposure was noted for propoxur at $21.2 \%$ $(165 / 777)$ of the infants. For maternal hair which is the best matrix for maternal exposure, there were ten pesticides with positive exposure including lead, mercury, arsenic, cadmium, propoxur, malathion, chlorpyrifos, bioallethrin, pretilachlor, and DDT. However, evidence of exposure to only six pesticides such as arsenic, lead, cadmium, mercury, propoxur and chlorpyrifos were noted in infant hair.

Table 5 shows the ABR wave latency measures in infants with hearing loss defined as ABR wave $V$ thresholds greater than $40 \mathrm{~dB}$ compared with those without hearing loss ( $<40 \mathrm{~dB}$ ABR wave $\mathrm{V}$ threshold). This serves as a good reference for the next table that examines effects on $A B R$ latencies following infant exposure to propoxur.

The differences in latencies (Wave I, III, V) and interpeak latencies (IPLs I-III, I-V, III-V) in auditory brainstem responses between infants exposed (with positive pesticide exposure, maternal hair and meconium) and infants unexposed (with negative pesticide exposure, maternal hair and meconium) to propoxur are shown in Table 6. With propoxur exposure (as detected in meconium among infants), ABR testing at $80 \mathrm{db}$ showed significant differences in the latency of wave III and IPL I-III on the right, wave III, V and IPL I-III both on the left ears. No major differences were seen at $60 \mathrm{~dB}$ and $40 \mathrm{~dB}$.

Table 1. Distribution of newborns' age when ABR was performed $(\mathrm{N}=686)$.

\begin{tabular}{|c|c|c|c|}
\hline & Age in months & Frequency & $\%$ \\
\hline & $1-3$ & 539 & 78.57 \\
\hline & $4-6$ & 50 & 7.29 \\
\hline & $7-9$ & 89 & 12.97 \\
\hline & $10-12$ & 8 & 1.17 \\
\hline & Total & 686 & 100.00 \\
\hline \multicolumn{4}{|c|}{2.41 months \pm 2.63} \\
\hline Range & \multicolumn{3}{|l|}{11 months, 1-12 } \\
\hline
\end{tabular}

Table 2. Laterality of newborns with Wave $\mathrm{V}$ threshold $\leq 40$ $\mathrm{dB}$ (with hearing loss) $(\mathrm{n}=15)$.

\begin{tabular}{lcl}
\hline Laterality & Frequency & \% \\
\hline Bilateral & 7 & 46.66 \\
Unilateral & & \\
Right & 4 & 26.67 \\
Left & 4 & 26.67 \\
Total & 15 & 100.00 \\
\hline
\end{tabular}

Table 3. Overall mean auditory brainstem response latencies, right and left ears.

\begin{tabular}{|c|c|c|c|}
\hline $\begin{array}{l}80 \mathrm{~dB} \\
\text { Parameters }\end{array}$ & Right & Left & $\mathrm{p}$ \\
\hline \multicolumn{4}{|c|}{ Absolute Wave } \\
\hline \multicolumn{4}{|c|}{ Latencies } \\
\hline I & $1.50( \pm 0.30)$ & $1.49( \pm 0.29)$ & 0.19 \\
\hline III & $4.23( \pm 0.33)$ & $4.23( \pm 0.35)$ & 0.67 \\
\hline V & $6.47( \pm 0.40)$ & $6.47( \pm 0.41)$ & 0.65 \\
\hline \multicolumn{4}{|c|}{ Interpeak Wave } \\
\hline \multicolumn{4}{|c|}{ Latencies } \\
\hline I-III & $2.73( \pm 0.30)$ & $2.76( \pm 0.30)$ & 0.04 \\
\hline III-V & $2.25( \pm 0.25)$ & $2.24( \pm 0.25)$ & 0.64 \\
\hline $\mathrm{I}-\mathrm{V}$ & $4.98( \pm 0.41)$ & $4.99( \pm 0.41)$ & 0.14 \\
\hline \multicolumn{4}{|l|}{$60 \mathrm{~dB}$} \\
\hline Parameters & Right & Left & $\mathrm{P}$ \\
\hline \multicolumn{4}{|c|}{ Absolute Wave } \\
\hline \multicolumn{4}{|c|}{ Latencies } \\
\hline I & $2.21( \pm 0.43)$ & $2.19( \pm 0.43)$ & 0.08 \\
\hline III & $4.80( \pm 0.48)$ & $4.80( \pm 0.48)$ & 0.31 \\
\hline $\mathrm{V}$ & $6.92( \pm 0.47)$ & $6.92( \pm 0.49)$ & 0.98 \\
\hline \multicolumn{4}{|c|}{ Interpeak Wave } \\
\hline \multicolumn{4}{|c|}{ Latencies } \\
\hline I-III & $2.58( \pm 0.37)$ & $2.61( \pm 0.36)$ & 0.49 \\
\hline III-V & $2.13( \pm 0.28)$ & $2.10( \pm 0.24)$ & 0.36 \\
\hline $\mathrm{I}-\mathrm{V}$ & $4.70( \pm 0.51)$ & $4.69( \pm 0.50)$ & 0.60 \\
\hline \multicolumn{4}{|l|}{$40 \mathrm{~dB}$} \\
\hline Parameters & Right & Left & $\mathrm{P}$ \\
\hline \multicolumn{4}{|c|}{ Absolute Wave } \\
\hline \multicolumn{4}{|c|}{ Latencies } \\
\hline I & $2.93( \pm 0.42)$ & $2.84( \pm 0.48)$ & 0.42 \\
\hline III & $5.38( \pm 0.41)$ & $5.42( \pm 0.45)$ & 0.002 \\
\hline V & $7.53( \pm 0.49)$ & $7.53( \pm 0.61)$ & 0.42 \\
\hline \multicolumn{4}{|c|}{ Interpeak Wave } \\
\hline \multicolumn{4}{|c|}{ Latencies } \\
\hline I-III & $2.41( \pm 0.36)$ & $2.54( \pm 0.35)$ & 0.00 \\
\hline III-V & $2.14( \pm 0.28)$ & $2.13( \pm 0.32)$ & 0.70 \\
\hline $\mathrm{I}-\mathrm{V}$ & $4.48( \pm 0.46)$ & $4.60( \pm 0.47)$ & 0.12 \\
\hline
\end{tabular}

Table 4. Frequency distribution of infants with positive maternal and infant environmental exposure to various pesticides.

\begin{tabular}{|c|c|c|c|}
\hline & \multicolumn{2}{|c|}{ Matrix } & \multirow[b]{2}{*}{ Meconium (\%) } \\
\hline & Maternal Hair(\%) & Infant Hair(\%) & \\
\hline \multicolumn{4}{|l|}{ Pesticides } \\
\hline Lead & 25.8 & 9.9 & 0 \\
\hline Cadmium & 0.2 & 9.9 & 0 \\
\hline Mercury & 24.7 & 9.9 & 0 \\
\hline Arsenic & 7.5 & 17.7 & 0 \\
\hline Malathion & 0.9 & 0 & 0.3 \\
\hline Chlorpyrifos & 0.1 & 0.1 & 0 \\
\hline Bioallethrin & 9.0 & 0 & 0.3 \\
\hline Pretilachlor & 0.1 & 0 & 0.8 \\
\hline DDT & 0.2 & 0 & 0.5 \\
\hline Propoxur & 9.9 & 0.3 & 21.2 \\
\hline Diazinon & 0 & 0 & 0.1 \\
\hline Cyfluthrin & 0 & 0 & 0.8 \\
\hline Cypermethrin & 0 & 0 & 1.5 \\
\hline DDE & 0 & 0 & 0.2 \\
\hline
\end{tabular}


Table 5. Comparison of latencies of ABR parameters between infants with hearing loss (Wave $\mathrm{V}$ threshold $>40$ $\mathrm{dB}$ ) and without hearing loss (Wave V Threshold $\leq 40 \mathrm{~dB}$ ).

\begin{tabular}{|c|c|c|c|c|c|c|}
\hline \multirow{3}{*}{$\begin{array}{l}80 \mathrm{~dB} \\
\text { Parameters }\end{array}$} & \multicolumn{2}{|c|}{ Right } & \multicolumn{4}{|c|}{ Left } \\
\hline & $(>40 \mathrm{~dB})$ & $(\leq 40 \mathrm{~dB})$ & $\mathrm{p}$ & $(>40 \mathrm{~dB})$ & $(\leq 40 \mathrm{~dB})$ & $\mathrm{p}$ \\
\hline & $(\mathrm{n}=11)$ & $(\mathrm{n}=677)$ & & $(\mathrm{n}=11)$ & $(\mathrm{n}=677)$ & \\
\hline \multicolumn{7}{|c|}{ Absolute Wave } \\
\hline \multicolumn{7}{|l|}{ Latencies } \\
\hline I & $1.79( \pm 0.52)$ & $1.50( \pm 0.29)$ & .00 & $2.02( \pm 0.53)$ & $1.48( \pm 0.27)$ & .00 \\
\hline III & $4.38( \pm 0.50)$ & $4.22( \pm 0.32)$ & .02 & $4.48( \pm 0.60)$ & $4.23( \pm 0.34)$ & .00 \\
\hline V & $6.53( \pm 0.60)$ & $6.47( \pm 0.40)$ & .10 & $6.67( \pm 0.71)$ & $6.47( \pm 0.40)$ & .00 \\
\hline \multicolumn{7}{|c|}{ Interpeak Wave } \\
\hline \multicolumn{7}{|l|}{ Latencies } \\
\hline I-III & $2.58( \pm 0.31)$ & $2.73( \pm 0.30)$ & .54 & $2.46( \pm 0.22)$ & $2.76( \pm 0.30)$ & .18 \\
\hline III-V & $2.15( \pm 0.24)$ & $2.25( \pm 0.25)$ & .91 & $2.20( \pm 0.22)$ & $2.24( \pm 0.25)$ & .85 \\
\hline $\mathrm{I}-\mathrm{V}$ & $4.74( \pm 0.49)$ & $4.66( \pm 0.35)$ & .27 & $4.98( \pm 0.41)$ & $5.00( \pm 0.40)$ & .23 \\
\hline $60 \mathrm{~dB}$ & \multicolumn{2}{|c|}{ Right } & \multicolumn{4}{|c|}{ Left } \\
\hline & $(>40 \mathrm{~dB})$ & $(\leq 40 \mathrm{~dB})$ & $\mathrm{p}$ & $(>40 \mathrm{~dB})$ & $(\leq 40 \mathrm{~dB})$ & $\mathrm{p}$ \\
\hline Parameters & $(\mathrm{n}=6)$ & $(\mathrm{n}=677)$ & & $(\mathrm{n}=11)$ & $(\mathrm{n}=677)$ & \\
\hline \multicolumn{7}{|c|}{ Absolute Wave } \\
\hline \multicolumn{7}{|c|}{ Latencies } \\
\hline I & $2.23( \pm 0.37)$ & $2.21( \pm 0.44)$ & .50 & $2.56( \pm 0.54)$ & $2.18( \pm 0.43)$ & .27 \\
\hline III & $4.89( \pm 0.46)$ & $4.80( \pm 0.38)$ & .33 & $5.06( \pm 0.63)$ & $4.80( \pm 0.48)$ & .08 \\
\hline V & $6.91( \pm 0.69)$ & $6.47( \pm 0.40)$ & .06 & $7.09( \pm 0.86)$ & $6.91( \pm 0.49)$ & .00 \\
\hline \multicolumn{7}{|c|}{ Interpeak Wave } \\
\hline \multicolumn{7}{|l|}{ Latencies } \\
\hline I-III & $2.61( \pm 0.34)$ & $2.58( \pm 0.37)$ & .73 & $2.44( \pm 0.20)$ & $2.61( \pm 0.36)$ & .06 \\
\hline III-V & $2.02( \pm 0.29)$ & $2.13( \pm 0.28)$ & .61 & $2.03( \pm 0.33)$ & $2.10( \pm 0.24)$ & .12 \\
\hline $\mathrm{I}-\mathrm{V}$ & $4.50( \pm 0.50)$ & $4.70( \pm 0.51)$ & .94 & $4.51( \pm 0.45)$ & $4.70( \pm 0.50)$ & .78 \\
\hline $40 \mathrm{~dB}$ & \multicolumn{2}{|c|}{ Right } & \multicolumn{4}{|c|}{ Left } \\
\hline & $(>40 \mathrm{~dB})$ & $(\leq 40 \mathrm{~dB})$ & $\mathrm{p}$ & $(>40 \mathrm{~dB})$ & $(\leq 40 \mathrm{~dB})$ & $\mathrm{p}$ \\
\hline Parameters & $(\mathrm{n}=11)$ & $(\mathrm{n}=677)$ & & $(n=11)$ & $(\mathrm{n}=677)$ & \\
\hline \multicolumn{7}{|c|}{ Absolute Wave } \\
\hline \multicolumn{7}{|l|}{ Latencies } \\
\hline I & $2.87( \pm 0.14)$ & $2.93( \pm 0.42)$ & .35 & $2.81( \pm 0.36)$ & $2.84( \pm 0.49)$ & .77 \\
\hline III & $5.33( \pm 0.47)$ & $5.38( \pm 0.41)$ & .45 & $5.33( \pm 0.40)$ & $5.42( \pm 0.45)$ & .78 \\
\hline V & $7.44( \pm 0.70)$ & $7.53( \pm 0.49)$ & .03 & $7.57( \pm 0.73)$ & $7.53( \pm 0.61)$ & .34 \\
\hline \multicolumn{7}{|c|}{ Interpeak Wave } \\
\hline \multicolumn{7}{|c|}{ Latencies } \\
\hline I-III & $2.73( \pm 0.42)$ & $2.40( \pm 0.35)$ & .94 & $2.56( \pm 0.01)$ & $2.54( \pm 0.35)$ & .06 \\
\hline III-V & $2.11( \pm 0.51)$ & $2.14( \pm 0.28)$ & .11 & $2.09( \pm 0.33)$ & $2.13( \pm 0.32)$ & .47 \\
\hline $\mathrm{I}-\mathrm{V}$ & $4.76( \pm 0.52)$ & $4.48( \pm 0.46)$ & .95 & $4.70( \pm 0.49)$ & $4.59( \pm 0.47)$ & .81 \\
\hline
\end{tabular}

There were differences found sporadically in different waves and pesticides. In some cases, exposure to certain pesticides was found in 1 or 2 infants only, yet effects could be more pronounced as in diazinon, found in meconium of only one infant with abnormal $A B R$ wave $V$ threshold greater than $80 \mathrm{db}$ suggestive of severe to profound hearing impairment.

Correlating exposures to pesticides and hearing loss (Tables 7-9), 2 infants had exposure to propoxur, with a $1.4 \%$ risk of hearing loss, lower compared to the $2.7 \%$ risk of hearing loss in infants without exposure. On the other hand, 1 infant exposed to cypermethrin had hearing loss, with a $6.25 \%$ risk, higher compared to the unexposed group of
Table 6. Comparison of absolute wave latencies and interpeak wave latencies between infants with and without meconium exposure to environmental pesticide propoxur.

\begin{tabular}{|c|c|c|c|c|c|c|}
\hline \multicolumn{7}{|l|}{$80 \mathrm{~dB}$} \\
\hline \multirow[t]{2}{*}{ Latencies } & \multicolumn{2}{|c|}{ Right } & \multicolumn{4}{|c|}{ Left } \\
\hline & Exposed & Unexposed & $\mathrm{p}$ & Exposed & Unexposed & $\mathrm{p}$ \\
\hline I & $1.50 \pm .27$ & $1.51 \pm .31$ & .75 & $1.48 \pm .27$ & $1.49 \pm .30$ & .75 \\
\hline III & $4.16 \pm .31$ & $4.25 \pm .33$ & .006 & $4.18 \pm .35$ & $4.25 \pm .34$ & .03 \\
\hline $\mathrm{V}$ & $6.43 \pm .40$ & $6.49 \pm .40$ & .13 & $6.42 \pm .44$ & $6.49 \pm .40$ & .08 \\
\hline \multicolumn{7}{|c|}{ Interpeak Wave } \\
\hline \multicolumn{7}{|c|}{ Latencies } \\
\hline I-III & $2.66 \pm .30$ & $2.75 \pm .30$ & .002 & $2.70 \pm .31$ & $2.77 \pm .30$ & .02 \\
\hline III-V & $2.27 \pm .24$ & $2.24 \pm .25$ & .24 & $2.25 \pm .27$ & $2.24 \pm .25$ & .86 \\
\hline $\mathrm{I}-\mathrm{V}$ & $4.93 \pm .43$ & $4.99 \pm .41$ & .19 & $4.94 \pm .44$ & $5.00 \pm .40$ & .11 \\
\hline \multicolumn{7}{|l|}{$60 \mathrm{~dB}$} \\
\hline & \multicolumn{2}{|c|}{ Right } & \multicolumn{4}{|c|}{ Left } \\
\hline & Exposed & Unexposed & $\mathrm{p}$ & Exposed & Unexposed & $\mathrm{p}$ \\
\hline $\mathrm{I}$ & $2.17 \pm .40$ & $2.22 \pm .45$ & .35 & $2.17 \pm .35$ & $2.19 \pm .46$ & .69 \\
\hline III & $4.79 \pm .36$ & $4.86 \pm .39$ & .58 & $4.78 \pm .49$ & $4.80 \pm .49$ & .63 \\
\hline $\mathrm{V}$ & $6.93 \pm .45$ & $6.92 \pm .48$ & .77 & $6.94 \pm .49$ & $6.92 \pm .50$ & .66 \\
\hline \multicolumn{7}{|l|}{ IPL } \\
\hline I-III & $2.60 \pm .38$ & $2.58 \pm .36$ & .71 & $2.60 \pm .36$ & $2.62 \pm .36$ & .66 \\
\hline III-V & $2.15 \pm .23$ & $2.12 \pm .29$ & .29 & $2.13 \pm .26$ & $2.10 \pm .24$ & .12 \\
\hline $\mathrm{I}-\mathrm{V}$ & $4.74 \pm .49$ & $4.70 \pm .52$ & .49 & $4.70 \pm .47$ & $4.69 \pm .5$ & .86 \\
\hline \multicolumn{7}{|l|}{$40 \mathrm{~dB}$} \\
\hline & \multicolumn{2}{|c|}{ Right } & \multicolumn{4}{|c|}{ Left } \\
\hline & Exposed & Unexposed & $\mathrm{p}$ & Exposed & Unexposed & $\mathrm{p}$ \\
\hline I & $2.90 \pm .4$ & $22.93 \pm .43$ & .68 & $2.93 \pm .47$ & $2.81 \pm .49$ & .11 \\
\hline III & $5.39 \pm .4$ & $15.38 \pm .42$ & .70 & $5.46 \pm .43$ & $5.41 \pm .46$ & .27 \\
\hline V & $7.54 \pm .4$ & $97.52 \pm .50$ & .67 & $7.58 \pm .56$ & $7.52 \pm .64$ & .32 \\
\hline \multicolumn{7}{|l|}{ IPL } \\
\hline I-III & $2.41 \pm .39$ & $2.41 \pm .35$ & .99 & $2.49 \pm .39$ & $2.56 \pm .34$ & .25 \\
\hline III-V & $2.16 \pm .22$ & $2.14 \pm .30$ & .47 & $2.11 \pm .23$ & $2.13 \pm .35$ & .37 \\
\hline $\mathrm{I}-\mathrm{V}$ & $4.52 \pm .52$ & $4.47 \pm .44$ & .49 & $4.59 \pm .48$ & $4.60 \pm .47$ & .90 \\
\hline
\end{tabular}

Table 7. Association of propoxur exposure with status of hearing (ABR threshold).

\begin{tabular}{|c|c|c|c|}
\hline \multirow[b]{2}{*}{ Propoxur } & \multicolumn{2}{|c|}{ Presence of wave $\mathrm{V}$ at } & \multirow[b]{2}{*}{ Total } \\
\hline & $>40 \mathrm{~dB}$ & $\leq 40 \mathrm{~dB}$ & \\
\hline$(+)$ & 2 & 141 & 143 \\
\hline$(-)$ & 14 & 411 & 525 \\
\hline Total & 16 & 652 & 668 \\
\hline Riskexposed & $=2 / 143 \quad(1.4 \%)$ & & \\
\hline Riskunexposed & $=14 / 525(2.7 \%)$ & & \\
\hline Relative risk & $=0.52(0.12-2 / 30)$ & $\mathrm{P}=0.0565$ & \\
\hline \multicolumn{4}{|c|}{$1^{\text {St }}$ Infant: Wave V at $80 \mathrm{~dB}$ at the right $(1.6 \mathrm{ug} / \mathrm{L})$} \\
\hline \multicolumn{4}{|c|}{$2^{\text {nd }}$ Infant: Wave at $100 \mathrm{~dB}$ both ears $(0.32 \mathrm{ug} / \mathrm{L})$} \\
\hline
\end{tabular}

$1.34 \%$. Remarkably, this infant had propoxur exposure as well. One infant had pretilachlor exposure and a mild unilateral hearing loss with a $6.25 \%$ risk compared to the unexposed group with $1.99 \%$. 
Table 8. Association of cypermethrin exposure with status of hearing (ABR threshold).

\begin{tabular}{|c|c|c|c|}
\hline \multirow[b]{2}{*}{ Cypermethrinexp } & \multicolumn{2}{|c|}{ Presence of wave $\mathrm{V}$ at } & \multirow[b]{2}{*}{ Total } \\
\hline & $>40 \mathrm{~dB}$ & $\leq 40 \mathrm{~dB}$ & \\
\hline$(+)$ & 1 & 15 & 16 \\
\hline$(-)$ & 9 & 643 & 652 \\
\hline Total & 10 & 658 & 668 \\
\hline Riskexposed & $=1 / 16(6.25 \%)$ & & \\
\hline Riskunexposed & $=9 / 643(1.34 \%)$ & & \\
\hline Relative risk & $=4.53(0.61-33.64)$ & $\mathrm{P}=0.1019$ & \\
\hline \multicolumn{4}{|c|}{$1^{\text {st }}$ Infant: Wave V at $80 \mathrm{~dB}$ at the right $(2.82 \mathrm{ug} / \mathrm{L})$} \\
\hline
\end{tabular}

Table 9. Association of pretilachlor exposure with status of hearing (ABR threshold).

\begin{tabular}{llll}
\hline \multirow{2}{*}{ Pretilachlor } & \multicolumn{2}{c}{ Presence of wave V at } & \\
\cline { 2 - 3 }$(+)$ & $>\mathbf{4 0 d B}$ & $\mathbf{4 0 d B}$ & Total \\
\hline$(-)$ & 1 & 639 & 16 \\
Total & 13 & 644 & 652 \\
Riskexposed & 14 & & 668 \\
Riskunexposed & $=1 / 16(6.25 \%)$ & \\
Relative risk & $=13 / 652(1.99 \%)$ & & \\
3rd Infant: Wave V at $50 \mathrm{~dB}$ at the left $(0.48 \mathrm{ug} / \mathrm{L})$ & \\
\hline
\end{tabular}

However, there were no significant differences noted between the exposed and unexposed groups with regard to GMDS-hearing and speech subscale and general quotient scores.

Scrutinizing the 3 infants with exposures and hearing loss, there were low scores in GMDS scoring noted. In infant 1 with 2 exposures at unilateral moderate hearing loss, performance scores were low, although the general quotient scores were average at 6 and 12 months (Table 10). Infant 2 had propoxur exposure and bilateral profound hearing loss, with below average scores (Table 11). Infant 3 had pretilachlor exposure and unilateral mild hearing loss, showing modest scores in hearing and speech performance with average general quotient scores (Table 12).

Table 10. Griffith's Mental Development Scale of Infant 1. Infant 1 - positive exposure for propoxur and cypermethrin with moderate hearing loss

\begin{tabular}{|c|c|c|c|c|}
\hline Scores & $\begin{array}{l}\text { SQ } \\
6 \mathrm{mo}\end{array}$ & $\begin{array}{l}\% \text { tile } \\
6 \text { mo }\end{array}$ & $\begin{array}{l}S Q \\
12 \mathrm{mo}\end{array}$ & $\begin{array}{l}\% \text { tile } \\
12 \mathrm{mo}\end{array}$ \\
\hline Hearing/Language & 109 & 71 & 98 & 45 \\
\hline Performance & 62 & 1 & 90 & 27 \\
\hline General Quotient & \multicolumn{2}{|c|}{90.4 (average) } & \multicolumn{2}{|c|}{93.4 (average) } \\
\hline
\end{tabular}

Table 11. Griffith's Mental Development Scale of Infant 2. Infant 2 - positive for exposure to propoxur with bilateral profound hearing loss

\begin{tabular}{lllll}
\hline Scores & SQ & \%tile & SQ & \%tile \\
& 6 mo & $\mathbf{6 ~} \mathbf{~ m o}$ & $\mathbf{1 2}$ mo & $\mathbf{1 2}$ mo \\
\hline Hearing/Language & 42.3 & 0.5 & 68.6 & 2 \\
Performance & 53.84 & 0.5 & 90.1 & 27 \\
General Quotient & 47.6 (below average) & 75.6 (below average) \\
\hline
\end{tabular}

Table 12. Griffith's Mental Development Scale of Infant 3. Infant 3 - positive exposure to pretilachlor with mild unilateral hearing loss

\begin{tabular}{lllll}
\hline Scores & SQ & \%tile & SQ & \%tile \\
& $\mathbf{6} \mathbf{~ m o}$ & $\mathbf{6} \mathbf{~ m o}$ & $\mathbf{1 2}$ mo & $\mathbf{1 2} \mathbf{~ m o ~}$ \\
\hline Hearing/Language & 100 & 50 & 86 & 19 \\
Performance & 106 & 65 & 76 & 7 \\
General Quotient & 103.8 (average) & 90 (average) & \\
\hline
\end{tabular}

\section{Discussion}

While measures of central auditory effects among workers exposed to organophosphates have been reported, this study looks at early auditory effects in newborns with maternal exposure to environmental products. Propoxur, cypermethrin and pretilachlor exposure may contribute to increased risk of hearing loss given possible effects on the fetus or newborns. Three (3/668, 0.45\%) with positive exposure to environmental toxins had wave $\mathrm{V}$ thresholds $>40 \mathrm{~dB}, 2$ of which at $\geq 80 \mathrm{~dB}$, and $1 / 668(0.15 \%)$ with multiple exposures had wave $\mathrm{V}$ threshold $\geq 80 \mathrm{~dB}$.

The risk of hearing loss with exposure to identified substances appears clinically significant whether these are subtle changes found in ABR wave latencies or wave $V$ threshold elevations. The GMDS scores show good correlation at least among infants with hearing loss and documented exposures to toxins.

In this cohort, despite the rarity of the condition, there seems to be an association between exposure to propoxur, cypermethrin, and pretilachlor and hearing loss. It is important to delineate the effects of these exposures and eliminate other causes for the hearing loss. Further analysis using multivariate regression may be employed to include all possible variables that may contribute to hearing loss, so that individual effects may be quantified.

This study, along with published studies on OAE and ABRs from our center encouraged us to push for legislation to institute newborn hearing screening so that even in farflung areas these babies can benefit from early identification and intervention for prevention of deleterious effects on neuro-development which include speech and hearing. The present study would be helpful in educating people in the community on the proper use of commonly available pesticides, in addition to motivating health regulatory bodies to further investigate effects, institute regulations in pesticide use, and conduct regular monitoring of burden of exposures.

\section{Conclusion}

Maternal exposure to some pesticides may contribute to an increased risk for hearing loss among infants in an agricultural community. Further monitoring of infants may be helpful to assess if these effects are reversible or permanent. 


\section{Acknowledgments}

We would like to acknowledge the assistance of the following in bringing the babies for hearing screening: Essie Ann Ramos, Abner Hornedo, Patrocinio Mateo, Philip Cruz, Lilibeth Avendano, Rubilyn Obando, Maribel Santiago, Roberta Briones, Rozza Villavicencio and Cecilia Santiago.

This paper was supported by a grant from the National Institute of Communication and Hearing Disorders (NICHD) IR01HD03942800IA US EPA RFA2001 (STAR-HI) No. R829395-01-0.

\section{References}

1. Ostrea EM Jr, Villanueva-Uy E, Beilawski DM, et al. Maternal hair - an appropriate matrix for detecting maternal exposure to pesticides during pregnancy. Environ Res. 2006; 101(3):312-22.

2. Colosio C, Tiramani M, Maroni M. Neurobehavioral effects of pesticides: state of the art. Neurotoxicology. 2003; 24(4-5):577-91.

3. Zou C, Zhao Z, Tang L, Chen Z, Du L. The effect of lead on brainstem auditory brainstem evoked potentials in children. Chin Med J. 2003; 116(4):565-8.

4. Counter SA, Vahter M, Laurell G, Buchanan LH, Ortega F, Skerfving S. High lead exposure and auditory sensory-neural function in Andean children. Environ Health Perspect .1997; 105(5):522-6.

5. Bleecker ML, Ford DP, Lindgren KN, Scheetz K, Tiburzi MJ. Association of chronic and current measures of lead exposure with different components of brainstem auditory evoked potentials. Neurotoxicology. 2003; 24(4-5):625-31.

6. Tan-Laxa MA, Sison-Switala C, Rintelman W, Ostrea EM Jr. Abnormal auditory brainstem response among infants with prenatal cocaine exposure. Pediatrics. 2004; 113(2):357-60.

7. Murata K, Weihe P, Renzoni A, et al. Delayed evoked potentials in children exposed to methylmercury from seafood. Neurotoxicol Teratol. 1999; 21(4):343-8.

8. Ostrea EM Jr, Bielawski DM, Posecion NC Jr, et al. A comparison of infant hair, cord blood and meconium analysis to detect fetal exposure to environmental pesticides. Environ Res. 2008; 106(2):277-83.

9. Teixeira CF, Brandao MFA. Effects of agro-chemicals on the auditory system in rural workers. Cad Inf Prev Acid. 1998; 19:218.

10. Teixeira CF, Giraldo Da Silva Augusto L, Morata TC. Occupational exposure to insecticides and their effects on the auditory system. Noise Health. 2002; 4(14):31-9.

11. Chiong CM, Ostrea EM Jr, Reyes A, Llanes EG, Uy ME, Chan A. Correlation of hearing screening with developmental outcomes in infants over a 2-year period. Acta Otolaryngol (Stockh). 2007; 127(4):3848. 